\title{
PAINFUL OPHTHALMOPLEGIA OF RIGHT EYE IN 40-YEAR-OLD FEMALE - DIAGNOSED AS A CASE OF TOLOSA-HUNT SYNDROME
}

\author{
SALMA U ${ }^{1}$, KHAN NA $^{2}$,SARKER MAS ${ }^{3}$, NAHAR $\mathrm{S}^{4}$, ARA $\mathrm{R}^{5}$

\begin{abstract}
:
Tolosa-Hunt Syndrome (THS) is a painful opthalmoplegia caused by nonspecific inflammation of cavernous sinus or superior orbital fissure. Here, we present a case of THS who presented with severe unilateral headache and opthalmoplegia, responded dramatically with systemic steroid.
\end{abstract}

Key words: Tolosa-Hunt Syndrome, ophthalmoplegia

J Dhaka Med Coll. 2015; 24(2) : 160-162.

\section{Introduction}

Tolosa-Hunt syndrome (THS) is a rare disorder indicated by recurrent painful opthalmoplegia caused by non-specific inflammation of the cavernous sinus or superior orbital fissure (SOF). The disease shares histopathological features with idiopathic orbital pseudotumour; however, owning to its anatomical location, it produces characteristics clinical manifestation. ${ }^{1}$ Recurrent retro-orbital pain, with palsies of the third, fourth or sixth cranial nerves as well as the first and second divisions of the trigeminal nerve, are typical. Clinically, immediate response to steroid therapy is a hallmark of the condition.

The clinical presentation of THS has a wide differential diagnosis, and timely and appropriate imaging - as an adjunct to pertinent laboratory investigations - can greatly assist clinicians with early accurate diagnosis and management.

\section{Case Report}

A 40-year old lady presented with a severe right sided headache, was throbbing nature and associated with vomiting for 4 times. Headache was persistent and progressively increasing for twelve hours. Headache was not associated with any aura, convulsion or unconsciousness. On the next day she developed dropping of the right eyelid. The patient was afebrile and there was no weakness of any limb or altered sensation. There is also no history of head trauma and her bowel bladder habit was normal.

On clinical examination her pulse was76 bit per minute (regular); BP 120/85mm of Hg. She had complete ptosis on right side, pupil was dilated and both direct and consensual light reflex was absent. There was complete ophthalmoplegia on right side. Her pain and touch sensation was impaired along the distribution of ophthalmic division of trigeminal nerve. Fundoscopy was normal.

Her investigation showed: WBC $12 \times 10^{9} / \mathrm{L}$, $85 \%$ neutrophil, ESR 60mm in first hour, total cholesterol was $369 \mathrm{mg} / \mathrm{dl}$,ANA negative, CSF leucocytes $40 / \mathrm{cmm}$, lymphocyte $95 \%$.CT scan of brain showed small lacunar infarct in the right side centrum semi ovale. MRI of brain asymmetrical widening of right parasellar region.

1. Dr. Umma Salma, Associate Professor of Medicine, Dhaka National Medical College \& Hospital, Dhaka.

2. Dr. Nurul Amin Khan, Associate Professor of Neurology, Dhaka National Medical College \& Hospital, Dhaka.

3. Dr. Mohammad Abdus Sattar Sarker, Assistant Professor of Medicine, Sir Salimullah Medical College \& Mitford Hospital, Dhaka.

4. Dr. Shamsun Nahar, Assistant Professor of Medicine, Dhaka National Medical College \& Hospital, Dhaka.

5. Dr. Rowsan Ara, Associate Professor of Medicine, Green Life Medical College Hospital, Dhaka

Correspondence : Dr. Umma Salma, Associate Professor of Medicine, Dhaka National Medical College \& Hospital, Dhaka. 


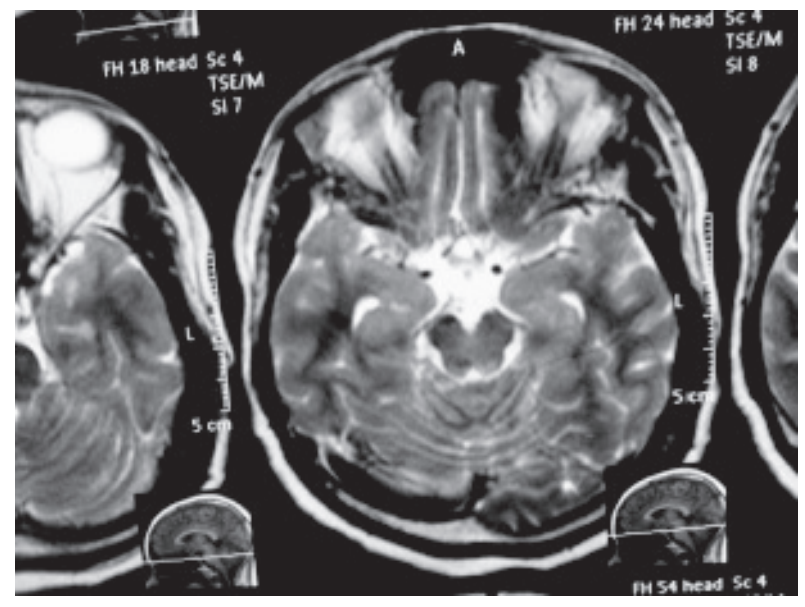

Fig. 1: MRI of Brain asymmetrical widening of right parasellar region

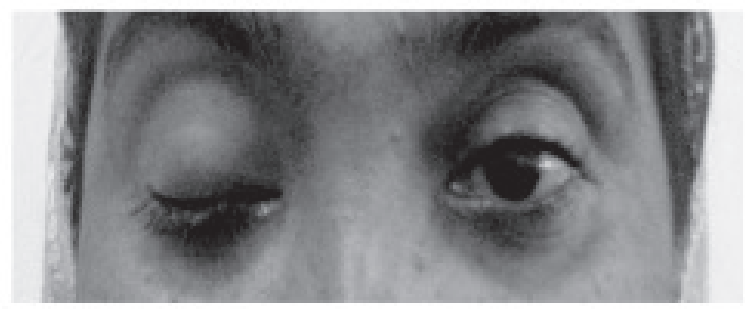

A. Ptosis

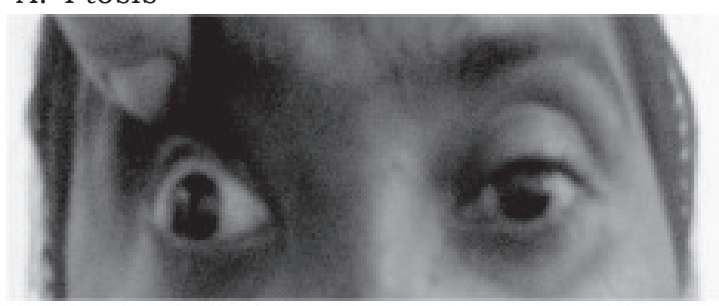

B. Before Treatment

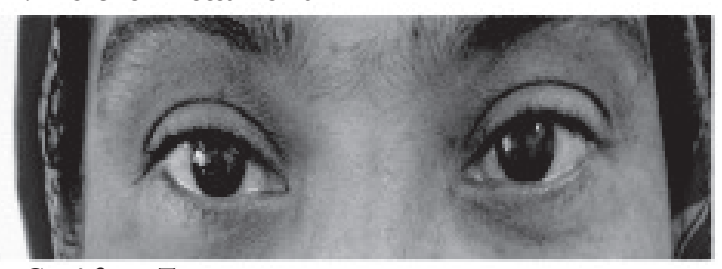

C. After Treatment

Fig.-2: Ptosis of the patient's right eye

A. Ptosis

B. Before Treatment

C. After Treatment

The patient was treated with oral steroids and showed significant relief of symptoms over following 48 hours. During discharge after 7 days her ptosis was not completely resolved but complete resolution of ptosis as well as oculomotor nerve palsy was found during followup after one month.

\section{Discussion}

Tolosa first described the condition in 1954, in a patient with unilateral recurrent painful opthalmoplegia involving cranial nerves III, IV, $\mathrm{VI}$ and $\mathrm{V}_{1}$. The patient was imaged using carotid angiography and segmental narrowing of the carotid siphon was seen. ${ }^{1}$

Hunt et al. described 6 patients with similar clinical finding in 1961, and proposed a lowgrade non-specific inflammation of the cavernous sinus and its walls as the cause of the syndrome. Pathologically infiltration of lymphocytes and plasma cells as well as thickening of the dura mater was seen. ${ }^{1}$ The condition was termed Tolosa-Hunt syndrome by Smith and Taxal in $1966 .^{2}$ The latter authors stressed the importance ofthe dramatic rapid response to steroid therapy.

In 1988 , THS criteria were provided by the International Headache Society (IHS), and further revised in 2004 (Table I). ${ }^{3,4}$

\section{Table I}

THS diagnostic criteria

A. One of the more episodes of unilateral orbital pain persisting for weeks if untreated

B. Paresis of one or more of the third, fourth and/or sixth cranial nerves and/or demonstration of granulomas by MRI or biopsy

C. Paresis coincides with the onset of pain or follows it within 2 weeks

D. Pain and pareis resolve within 72 hours when treated adequately with corticosteroids

E. Other causes have been excluded by appropriate investigations.

Our patient fulfilled all the criteria provided by IHS. She presented within 12 hours of pain onset and she had paresis of IV, V, VI cranial nerves as well as first division of the trigeminal nerve. Her pain resolved within 48 hours of steroid therapy and other differential diagnosis was excluded by imaging of the brain. 
Neuroimaging - in particular MRI - is an essential part of the workup of any patient presenting with features of THS, as these features are non-specific and have a wide differential diagnosis, including meningioma, sarcoidosis, pituitary tumours, tuberculous meningitis (TBM) and lymphoma, Wegener granulomatosis, ophthalmoplegic migraine. ${ }^{2}$ MRI findings classically demonstrate a softtissue mass lesion involving the SOF or cavernous sinus. Signal characteristics are typically hypointense to fat and isointense to muscle on short TR/TE sequences and isointense to fat on long TR/TE sequences. ${ }^{5}$ Significant enhancement of the mass lesion is demonstrated on $\mathrm{CE}$ sequences. Of the particular value is the post-contract fatsaturated thin-slice coronal images through the orbital apex and cavernous sinus.

Administration of systemic steroid for 48 hours in a patient with THS produces a dramatic response in painful ophthalmoplegia that allows differentiation of this cause from other conditions of painful ophthalmoplegia. ${ }^{6}$ Even though there is no standardize dose specified in the literature, this type of the treatment with steroid at a dose of $1 \mathrm{mg} / \mathrm{kg} /$ day tapered slowly over three to four months has been well received. ${ }^{3}$

\section{Conclusion}

TSH is rare disorder, and diagnosis of exclusion. Steroid treatment if the cornerstone in the management of THS. In the presence of painful opthalomoplegia, the finding by MRI of cavernous sinus englargement and rapid resolution of the clinical symptoms with steroid therapy are characteristics.

\section{References:}

1. Som PD, Curtin HD. Head and Neck Imaging. $4^{\text {th }}$ ed. St Louis: Mosby; 2003: p.587-91.

2. Sathyanathan BP, Rajasundaram $R$, Sankaravadivelu ST, Nadhamuni K. A case report of Tolosa-Hunt Syndrome-MR imaging appearance. Ind J RadiolImag 2006;16(1): 97-8.

3. Mendez JA, Arias CR, Sanchez D, et al. Painful ophthalmoplegia of the left eye in 19-year-old female with an emphasis on Tolosa-Hunt syndrome: a case report. Cases Journal 2009; 2:8271.

4. Mora-de-Onate J, Pascual-Perez-Alfaro R, Izquierdo-Vazquez C, Gonzalez-Ruiz M, Aguirrebena-Olmos A, Diez-Villalba R. Painful opthamlmoplegia (pseudotumour of the orbit and Tolosa-Hunt Syndrome). Arch SocEspOftalmol 2007;82: 509-12.

5. Yousem DM, Atlas SW, Grossman RI, Sergott RC, Savino PJ, Bosley TM. MR imaging of Tolosa-Hunt Syundrome. AJNR 1990;154: 167-70.

6. Smith FW, Singh AK: Nuclear magnetic resonance tomography of the orbits at $3.4 \mathrm{MHz} \mathrm{Br} \mathrm{J}$ Radiol 1985 ; 58:947-57. 